\title{
FOUNDATIONS OF OFFENDER
}

REHABILITATION

SHARON CASEY, ANDREW DAY, JAMES VESS AND TONY WARD

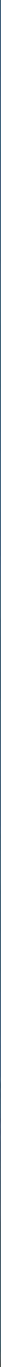




\section{Foundations of Offender Rehabilitation}

'This book forges a much-neglected link between etiological theories and rehabilitation models, risk assessment, formulation and treatment planning. It provides an integrated resource that will improve the conceptual competence of those in training, post-qualification professionals who are looking to make the transition into forensic practice and programme designers alike'.

Devon Polaschek, Associate Professor, Criminal Justice Psychology, Victoria University of Wellington, New Zealand.

The past three decades have seen dramatic changes in the way in which the criminal justice system responds to those who break the law. The old claim in the field of correctional psychology that 'nothing works' has strongly been refuted in the face of evidence that rehabilitation programmes do make a difference. The graduate student in forensic psychology could easily be overwhelmed by the plethora of information now available.

This new textbook offers a comprehensive approach to forensic and correctional psychology, demonstrating how theory and practice can be applied and integrated. Written by internationally recognized experts within the field, the authors guide the reader through the core theories and concepts that underpin forensic practice within the legal systems of different countries (UK, USA, Canada, Australia and Singapore), show how this knowledge informs current thinking in offender rehabilitation and reintegration and provide a series of case studies looking at sexual offenders, female offenders, juveniles and offenders with mental disorders.

This book is the perfect overview for graduate students of forensic and correctional psychology engaged with offender rehabilitation and assessment and the psychology of law.

Sharon Casey is a Senior Lecturer at Deakin University and member of the Clinical Forensic Group within the Deakin Forensic Psychology Centre.

Andrew Day is Professor in Forensic Psychology and Director of the Forensic Psychology Centre at Deakin University.

James Vess has over 25 years of clinical and research experience with forensic populations. He is a Senior Lecturer and a member of the Forensic Psychology Centre at Deakin University.

Tony Ward, MA(Hons), PhD, DipClinPsyc, is Professor of Psychology at Victoria University, Wellington, New Zealand. 


\title{
Foundations of Offender Rehabilitation
}

\author{
Sharon Casey, Andrew Day, \\ James Vess and Tony Ward
}

\author{
Routledge \\ Taylor \& Francis Group \\ LONDON AND NEW YORK
}


First published 2013

by Routledge

2 Park Square, Milton Park, Abingdon, Oxon, OX14 4RN

Simultaneously published in the USA and Canada

by Routledge

711 Third Avenue, New York, NY 10017

Routledge is an imprint of the Taylor \& Francis Group, an informa business

(C) 2013 Sharon Casey, Andrew Day, James Vess and Tony Ward

The right of Sharon Casey, Andrew Day, James Vess and Tony Ward to be identified as authors of this work has been asserted by them in accordance with the Copyright, Designs and Patent Act 1988.

All rights reserved. No part of this book may be reprinted or reproduced or utilised in any form or by any electronic, mechanical, or other means, now known or hereafter invented, including photocopying and recording, or in any information storage or retrieval system, without permission in writing from the publishers.

Trademark notice: Product or corporate names may be trademarks or registered trademarks, and are used only for identification and explanation without intent to infringe.

British Library Cataloguing in Publication Data A catalogue record for this book is available from the British Library

Library of Congress Cataloging in Publication Data

A catalog record has been requested for this book

ISBN: 978-0-415-67916-9 (hbk)

ISBN: 978-0-415-67917-6 (pbk)

ISBN: 978-0-203-12681-3 (ebk)

Typeset in Times New Roman

by Cenveo Publisher Services 


\section{Contents}

List of tables

viii

List of figures

$\mathrm{x}$

About the authors

$\mathrm{xi}$

Foreword

xiii

Acknowledgement

$\mathrm{XV}$

\section{PART 1}

Theoretical foundations

1 Theories of offending

Theories of crime and criminal behaviour 3

Level I: Society 4

Level II: Community 6

Level III: Social groups 7

Level IV: Criminal acts and events 14

Level V: Individual level 17

Conclusion 32

2 Theories of offender rehabilitation

Features of effective offender rehabilitation 34

The RNR of offender rehabilitation 37

The GLM 41

Conclusion 46

\section{PART 2}

From theory to practice

3 Theories of behaviour and behaviour change

Self-determination theory 50

Social cognitive theory 55 
vi Contents

Self-regulation theory 58

Behaviour enaction models 63

Cognitive behavioural theory 68

Conclusion 78

4 Forensic assessment and case formulation

Psychological assessment 81

Assess the offending behaviour 85

Limitations and ethical issues of a functional analysis

approach to risk formulation 100

Case formulation 102

Case example 104

Conclusion 111

\section{PART 3}

Practice examples: Working with different groups

5 Sex offenders

Prevalence of sex offending and sex offenders 115

Aetiology of sexual offending 116

Assessment of sex offenders 117

Sex offender treatment: Current practice 120

Case example 122

6 Violent offenders

Understanding violence 129

Violent offender treatment 131

Case example 133

7 Substance use

Theoretical explanations of the drug-crime nexus 140

Assessment issues 142

Substance abuse treatment 143

Case example 147

8 Female offenders

The aetiology of female offending: Gendered-specific

needs and offence pathways 153

Assessment of female offenders 154

Treatment issues for female offenders 156

Case example 157 
9 Young offenders

Base rates 164

Assessing risk 165

Interventions 166

Case example 168

10 Mentally disordered offenders

The prevalence of mental illness among offenders 174

Treatment of mentally disordered offenders 177

Case example 178

11 Professional practice

Codes and guidelines 185

Specific issues for ethical professional practice 185

Supervision 190

Conclusion 191

Glossary

References

Index 


\section{Tables}

1.1 Theories of crime: Structural to agency 4

1.2 Implications of Level I theories for offender rehabilitation 6

1.3 Implications of Level II theories for offender rehabilitation 7

1.4 Risk factors for delinquency and other antisocial behaviour 13

1.5 Protective factors associated with delinquency and other antisocial behaviour 14

1.6 Implications of Level III theories for offender rehabilitation 15

1.7 Implications for Level IV theories for offender rehabilitation 17

1.8 Major constructs of social cognitive theory, definitions and change strategies

1.9 Implications of Level IV theories for offender rehabilitation 31

3.1 Behaviour change techniques and illustrative theoretical frameworks

3.2 Implications for self-determination theory for offender rehabilitation

3.3 Implications of social cognitive theory for offender rehabilitation

$\begin{array}{lll}3.4 & \text { Implications of self-regulation for offender rehabilitation } & 63 \\ 3.5 & \text { Stages of change model and potential change strategies } & 65\end{array}$

3.6 Implications of behaviour enaction theory for offender rehabilitation

3.7 Commonly held implicit theories of sexual offenders and examples associated cognitive distortions

3.8 Common schema modes in borderline personality disorder and treatment objectives for achieving health adult mode

3.10 Implications of cognitive-behavioural theories for offender rehabilitation

4.1 Examples of risk assessment tools

4.2 How to conduct a functional analysis of offending behaviour $\quad 89$

4.3 Offence pathways checklist 91

4.4 Core beliefs associated with mental health problems 94 
4.5 Proposed structure for assessment of primary goods 101

$\begin{array}{lll}4.6 & \text { Features of a good formulation } & 104\end{array}$

11.1 Examples of circumstances in which confidentiality
may not be offered to forensic clients

11.2 Differences between therapeutic and forensic relationships 188 


\section{Figures}

1.1 Mechanism through which moral self-sanctions are selectively activated and disengaged from detrimental behaviour at different points in the self-regulatory process

3.1 Self-determination continuum with types of motivation and regulatory styles, loci of causality

and corresponding processes

3.2 Negative feedback loop

3.3 Theoretical framework of TTM of change 64

3.4 Stages with relevant process of change 


\section{About the authors}

\section{Dr Sharon Casey}

Sharon Casey is a Senior Lecturer at Deakin University and member of the Clinical Forensic Group within the Deakin Forensic Psychology Centre. She was formerly Programme Director of the Master of Psychology (Forensic) programme at the University of South Australia. Her research interests include substance use, juvenile offending, scale development and validation, and psychology and the law. Dr Casey has worked extensively with correctional agencies both in Australia and overseas in the development, provision and evaluation of offender rehabilitation programmes and the provision of training. She currently holds an Australian Research Council Linkage Grant (in conjunction with Corrective Services New South Wales) undertaking a longitudinal analysis of recidivism rates for offenders completing substance use rehabilitation programmes across different treatment modalities.

\section{Dr Andrew Day}

Andrew Day is Professor in Forensic Psychology and Director of the Forensic Psychology Centre at Deakin University. He has a clinical background, previously working as a clinical and forensic psychologist in both the UK and Australia and is particularly interested in the application of psychological thought and practice to the correctional setting. Professor Day is a member of the Australian Psychological Society's Colleges of Clinical and Forensic Psychology. His current research interests centre around the development of therapeutic regimes within prison settings, effective practice with offenders from Aboriginal and Torres Strait Islander cultural backgrounds in Australia, and the role that anger plays in aggressive and violent behaviour.

\section{Dr James Vess}

James Vess has over 25 years of clinical and research experience with forensic populations. He received his $\mathrm{PhD}$ in clinical psychology from Ohio State University in the United States, and then served in a variety of treatment, assessment and supervisory roles at Atascadero State Hospital, the maximum security forensic psychiatric facility in California. He was subsequently a Senior Lecturer at Victoria University of Wellington, New Zealand and Deakin University in 
Victoria, Australia, where his research has focused primarily on risk assessment with violent and sexual offenders, as well as public policy dealing with high-risk offenders. He has remained active in forensic practice, and has provided expert witness evidence in a variety of High Court and Court of Appeals cases for Preventive Detention and Extended Supervision in both New Zealand and Australia. He is now a subject matter expert and project manager at the National Center for Telehealth and Technology in the Madigan Army Medical Center at Joint Base Lewis-McChord in Tacoma Washington.

\section{Dr Tony Ward}

Tony Ward, MA(Hons), PhD, DipClinPsyc, is currently Professor of Clinical Forensic Mental Health at Deakin University, Melbourne Australia. He was formerly Director of the Kia Marama Sexual Offenders' Unit at Rolleston Prison in New Zealand, and has taught both clinical and forensic psychology at Victoria, Canterbury and Melbourne Universities. He has authored over 300 academic publications and his research interests include the rehabilitation and desistance process in offenders, cognition and offenders, evolutionary approaches to crime, and ethical issues in forensic and correctional psychology. Professor Ward is the developer of the Good Lives Model (GLM) and has published numerous books, book chapters and academic articles on this model since 2002 . He is currently working on a research project with Dr Gwenda Willis and Dr Jill Levenson investigating the degree to which North American treatment programmes for sex offenders adhere to the basic conceptual underpinnings of the GLM. 


\section{Foreword}

The field of offender rehabilitation has undergone a process of substantial change over the years, from an early period of largely atheoretical and empirically unsubstantiated optimism, through assertions that nothing works to a focus on what works for contributing to positive changes in offenders and reductions in recidivism. Relatively recent evidence suggests that certain types of interventions can have a significant effect in reducing reoffending and managing the risk posed by some types of offenders, although general recidivism rates remain high for many offenders, as well as for certain known subgroups within offender populations such as violent and sexual offenders. Despite a burgeoning professional literature on offender rehabilitation, what has often been missing is an explicit articulation of the theoretical underpinnings of offender rehabilitation, and the development of assessment and intervention approaches that are clearly based on these theories. In this book we review a variety of theories of offending behaviour and current models of offender rehabilitation. This is followed by a consideration of available theories of behaviour change. This is an area that we believe is sometimes insufficiently utilized in attempts to develop and implement effective rehabilitation programmes with offenders.

The theoretical and empirical framework for offender rehabilitation should also guide forensic assessment and case formulation. In this book we provide an approach to the assessment of offenders that draws from available theoretical and empirical sources of information. But assessment is optimally useful only when it is integrated into an aetiologically explanatory case formulation for the offender being assessed. Consideration is therefore given to the development of effective case formulation, which should always form the basis for treatment planning, intervention and ongoing risk management.

The second half of the book applies the approach developed in the first half to specific populations of offenders. The chapter on sex offenders presents the fundamentals of current risk assessment practice, and considerations of applying assessment findings and case formulation to sex offender treatment. This is followed by a similar set of considerations for the assessment, case formulation and intervention with violent offenders. Substance abuse is a common and widespread phenomenon among offenders of all types and a chapter is, therefore, devoted to examining the current state of knowledge in the assessment and 


\section{xiv Foreword}

treatment of this set of problem behaviours. Female offenders have historically made up a relatively small portion of the total offender population, but their involvement in the criminal justice system is nonetheless substantial and may be growing. The chapter on female offenders considers the unique characteristics and concerns presented by this group, as does the following chapter considering a practice approach to the assessment and treatment of young offenders. Finally, the special needs and specific challenges of mentally disordered offenders are discussed. Each chapter includes a detailed case example to illustrate the approach to assessment, case formulation and rehabilitation that we are advocating.

The final chapter of the book presents some of the unique features of professional practice in the area of offender rehabilitation. Working in this area requires that the practitioner not only possess a solid set of clinical skills, but also specialized knowledge and awareness of the criminal justice context in which any work occurs. Consideration must be given to the special nature of informed consent, confidentiality, role boundaries and professional ethics when working with offenders. Our intent in writing this book is to present a specifically focused resource to the developing and practising professional that articulates the link between the theoretical and empirical foundations of offender rehabilitation, and provides a practical approach to working in this challenging but important field. We hope that you will find it a useful resource. 


\section{Acknowledgement}

This book emerged as a result of a collaboration between the authors, the Singapore Prison Service and the Ministry of Youth, Community and Sports in Singapore. We are grateful for their support and commitment to the development of psychological practice. 
